\title{
The duration of channel drying affects survival of Gammarus pulex (Amphipoda: Gammaridae) within subsurface sediments: an experimental flume study
}

\author{
Atish N. Vadher · Jonathan Millett $\cdot$ Rachel Stubbington $\cdot$ Paul J. Wood
}

Received: 27 July 2017/Revised: 4 May 2018/Accepted: 14 May 2018/Published online: 11 June 2018

(C) The Author(s) 2018

\begin{abstract}
Field studies have demonstrated that benthic fauna use hyporheic sediments during drying events in temporary rivers, but the factors influencing the survival of fauna in subsurface sediments remain poorly quantified. Laboratory mesocosm experiments were conducted to determine how the length of drying events $(1,7,14$ and 21 days) influenced the survivorship of Gammarus pulex (L.) (Amphipoda: Gammaridae). The water level was reduced to $5 \mathrm{~cm}$ below the substrate surface during drying experiments and held at $5 \mathrm{~cm}$ above the sediment surface during control experiments. The results demonstrate that G. pulex survivorship was reduced with increasing length of the experiment, particularly in the drying treatment compared to the control treatment. We show that G. pulex can persist in subsurface sediments for up to 21 days during surface drying. In view of interacting climatic
\end{abstract}

Handling editor: Nicholas R. Bond

A. N. Vadher · J. Millett · P. J. Wood

Department of Geography, Centre for Hydrological and

Ecosystem Sciences, Loughborough University,

Loughborough, Leicestershire, UK

\author{
A. N. Vadher $(\bowtie)$ \\ Faculty of Arts, Science and Technology, University of \\ Northampton, Northampton NN2 6JD, UK \\ e-mail: Atish.Vadher@Northampton.ac.uk \\ R. Stubbington \\ School of Science and Technology, Nottingham Trent \\ University, Clifton Campus, Nottingham, UK
}

drivers and water resource pressures that are increasing the spatial and temporal occurrence of streambed drying, our results have important implications for stream management. Our results also highlight the utility of mesocosm-based studies for elucidating the abiotic controls of macroinvertebrate survival during stream drying events.

Keywords Intermittent rivers - Ephemeral streams · Streambed drying - Mesocosm experiment - Drought . Survivorship

\section{Introduction}

Temporary streams experience periods of reduced hydrological connectivity as surface water levels decline, often resulting in sections of the streambed becoming dry (Boulton, 2003; Larned et al., 2010). The ecological effects of surface water level reduction and drying on aquatic organisms potentially increase over time as abiotic conditions become increasingly unfavourable (Lake, 2003; Dewson et al., 2007; Lake, 2011). Flow cessation and surface drying events typically result in a reduction in the abundance of rheophilic taxa (Chessman, 2009; Verdonschot et al., 2015), an increased dominance of generalist taxa able to persist in isolated pools (Robson et al., 2011) and the persistence of a limited number of desiccationtolerant taxa in drying sediments (Stubbington et al., 
2009; Datry, 2012). An increased duration of flow intermittence and channel drying can reduce benthic and hyporheic faunal density and richness as taxa reach their physiological limits (Datry et al., 2007; Arscott et al., 2010; Lancaster \& Ledger, 2015), although recovery following flow resumption may occur quickly depending on refuge availability (Chester \& Robson, 2011). Studies investigating temporary streams have indicated that the duration of drying represents a primary control on the structure and diversity of communities (e.g. Feminella, 1996; Datry et al., 2014; Storey, 2016). Adaptations of temporary stream fauna that enhance resistance and resilience to surface drying include behavioural responses, for example movement into saturated subsurface sediments (Vander Vorste et al., 2016a; Vadher et al., 2017), life history adaptations, for example aestivation and diapause (Strachan et al., 2015) and physiological adaptations including desiccation tolerance of egg, juvenile or adult life stages (Stubbington et al., 2016).

Subsurface sediments represent a potential habitat and refuge for benthic macroinvertebrates during adverse environmental conditions (Williams \& Hynes, 1974; Stubbington, 2012). Although some studies have demonstrated that lotic benthic macroinvertebrates move into saturated subsurface sediments in response to severe low flows and surface water loss (e.g. Fenoglio et al., 2006; Wood et al., 2010; Vander Vorste et al., 2016a), others have reported limited or no evidence of subsurface refuge use (e.g. del Rosario $\&$ Resh, 2000; Young et al., 2011). These equivocal results illustrate that abiotic conditions in subsurface sediments are heterogeneous and that their use by benthic fauna depends on factors including substrate characteristics (Stubbington, 2012; Descloux et al., 2013; Vadher et al., 2017) and water quality (Lawrence et al., 2013). Such variability makes generalisation difficult, since predicting lotic community responses to drying is currently constrained by a lack of species-specific information. In light of predicted future increases in the frequency and duration of stream drying associated with climate change and other anthropogenic pressures (Ledger \& Milner, 2015; Pyne \& Poff, 2017), improved knowledge surrounding the influence of such changes on benthic invertebrate communities is becoming increasingly important. To control for heterogeneity within temporary streams, ex situ laboratory flume and mesocosm investigations have been undertaken to examine the effects of surface drying on aquatic invertebrate fauna (e.g. Ledger et al., 2011; Poznańska et al., 2013; Vadher et al., 2015; Vander Vorste et al., 2016b).

Gammarus pulex (L.) (Amphipoda: Gammaridae) is an ecologically important amphipod which functions as a processor of coarse particulate organic matter (Navel et al., 2010), a predator, and as prey of both invertebrates and fish across northwest Europe (MacNeil et al., 1997). It has been extensively used in laboratory mesocosm investigations (e.g. McGrath et al., 2007; Mathers et al., 2014; Stubbington et al., 2017) and occurs widely in benthic and subsurface habitats of perennial and temporary streams (Stubbington et al., 2009; Wood et al., 2010; Verdonschot et al., 2015). Gammarus pulex has been observed to actively migrate into subsurface sediments in response to surface drying in both field (e.g. Vander Vorste et al., 2016a) and laboratory (e.g. Vadher et al., 2015; Vander Vorste et al., 2016b; Vadher et al., 2017) investigations.

We examined the effect of increased duration of surface water loss and sediment drying on the survivorship of $G$. pulex within mesocosms in a recirculating flume. The mesocosms allowed flow velocity, water level, water quality (conductivity, dissolved oxygen, $\mathrm{pH}$ and temperature) and sediment characteristics to be controlled. Our aim was to determine the extent to which G. pulex can survive in sediments during drying events and the effect of dry period duration on survivorship.

\section{Materials and Methods}

\section{Development of the flume mesocosm}

The experiment was conducted using a laboratory flume $(219 \mathrm{~cm}$ long $\times 56 \mathrm{~cm}$ wide $\times 56 \mathrm{~cm}$ deep; adapted from Vadher et al., 2015). The flume was constructed using a $300 \mathrm{~L}$ capacity tank linked to a water cooler and pump to create a closed recirculating system held at a temperature of $12 \pm 0.5^{\circ} \mathrm{C}$ (Fig. 1). Five $20 \mathrm{~cm}^{3}$ mesocosms constructed from $3 \mathrm{~mm}$ aperture steel mesh were lined with $150 \mu \mathrm{m}$ mesh nylon netting and filled to a depth of $10 \mathrm{~cm}$ with prewashed coarse fluvial gravel (10-20 mm diameter). The mesocosms were placed adjacent to each other on a fine gravel base (2-4 mm diameter; Fig. 1). Water 


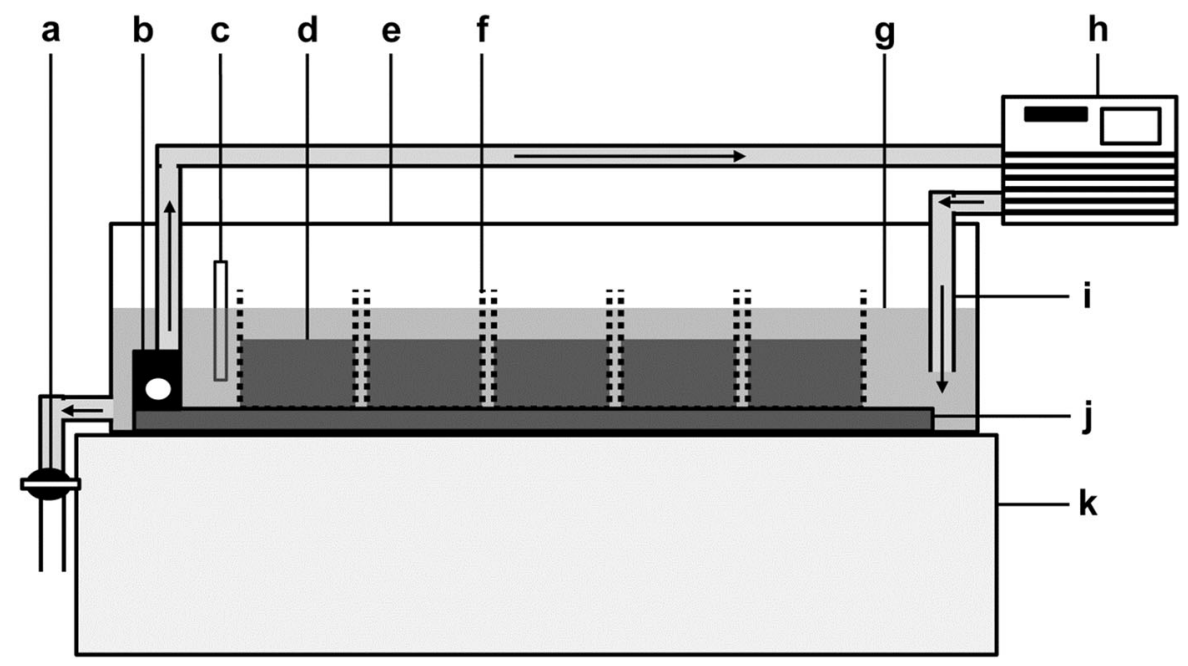

Fig. 1 Schematic cross section through the experimental flume. (a) ball valve to control water level; $(b)$ water pump; (c) ruler; (d) coarse gravel (10-20 mm) matrix; $(e)$ experimental tank; (f) mesocosm $(20 \mathrm{~cm} \times 20 \mathrm{~cm} \times 20 \mathrm{~cm})$; (g) water level

level was controlled using a ball valve and monitored (0.25 $\mathrm{mm}$ accuracy) using a ruler fixed to the inside wall of the flume (Fig. 1).

\section{Experimental procedure}

Twenty-four hours prior to each experiment, each mesocosm and its sediments were washed and the experimental tank filled with dechlorinated tap water to $5 \mathrm{~cm}$ above the substrate surface (Fig. 1) before being circulated until a temperature of $12{ }^{\circ} \mathrm{C}$ was recorded. Gammarus pulex was collected using a standard kick net $(900 \mu \mathrm{m}$ mesh, $230 \mathrm{~mm} \times 255 \mathrm{~mm}$ frame, $275 \mathrm{~mm}$ bag depth) from a riffle on Black Brook $\left(52^{\circ} 45^{\prime} 46.7^{\prime \prime} \mathrm{N}, 1^{\circ} 19^{\prime} 19.1^{\prime \prime} \mathrm{W}\right)$ in Loughborough (Leicestershire, UK). Specimens used in experimental trials were carefully removed from the net using tweezers and those $>5 \mathrm{~mm}$ in length were placed into a 5-1 container of stream water for immediate transport to the laboratory. Mixed preconditioned native leaf litter from the stream was thoroughly washed in the stream channel to remove attached stream fauna and returned to the laboratory to serve as a food source during experiments. Between four and six leaves (depending on size) were shredded and distributed through the gravel subsurface of each mesocosm. Ten G. pulex were then transferred into each of the five mesocosms (population density in
(5 cm above coarse gravel matrix); (h) water cooler; $(i)$ pipe; $(j)$ gravel base; $(k)$ platform. Arrows represent direction of flow. Not to scale (adapted from Vadher et al., 2015)

each mesocosm $=50$ G. pulex $\mathrm{m}^{-2}$ ) and left to acclimatise for approximately $30 \mathrm{~min}$ prior to water level reduction. This acclimation period has been demonstrated to be sufficient to allow individuals to complete initial exploratory movements and seek refuge between sediment clasts (Vadher et al., 2015).

To examine the effect of drying duration $(1,7,14$ and 21 days) on $G$. pulex survivorship, three replicate experiments were conducted for each duration in both drying (water level reduction) and control conditions (water level maintained at $5 \mathrm{~cm}$ above the coarse gravel surface), providing a total of 24 experiments (5 mesocosms per experiment; $n=120$ mesocosms). A water pump recirculated water through the tank at a constant rate of $41.71 \mathrm{~min}^{-1}$ for the duration of all experiments (drying and control conditions). After the initial faunal acclimation period, water level was reduced over a $2 \mathrm{~h}$ period from $5 \mathrm{~cm}$ above the gravel surface to $5 \mathrm{~cm}$ below the surface (dewatering rate of $5 \mathrm{~h} \mathrm{~cm}^{-1}$ ) by opening the ball valve and reducing water level by $1.25 \mathrm{~cm}$ every $15 \mathrm{~min}$. The rate of water level reduction was directly comparable to previous mesocosm (Vadher et al., 2015) and field research (Vadher et al., 2018) and provided a $5 \mathrm{~cm}$ refuge retaining free water in the subsurface sediments of the mesocosm. At the end of the water level reduction period, the flume was maintained at the 
same water level ( $5 \mathrm{~cm}$ saturated gravel), temperature and flow rate for the duration of each experiment.

Assessing G. pulex survivorship

Upon completion of each experiment, mesocosms were individually removed and the number of surviving G. pulex was determined. The contents of each mesocosm were carefully excavated into a steel tray (50 cm diameter) and rinsed so that all G. pulex could be removed and transferred into a beaker of dechlorinated tap water. The survivorship of G. pulex was determined by the number of live (moving) G. pulex present. Whole, non-mobile individuals were considered to have died during the experiment and absent individuals or body parts were assumed to reflect predation (McGrath et al., 2007) or decomposition following stranding above the waterline. Body parts (e.g. legs, antennae) were not recorded unless the head was observed.

Abiotic parameters

Prior to the start of each experiment, $\mathrm{pH}$, dissolved oxygen $\left(\mathrm{mg}^{-1}\right)$, temperature $\left({ }^{\circ} \mathrm{C}\right)$ and conductivity $\left(\mu \mathrm{S} \mathrm{cm}{ }^{-1}\right)$ were measured in the free water around each mesocosm using laboratory metres (Hanna Instruments, Bedfordshire, UK). At the end of each experiment, abiotic parameters were re-measured to determine the stability of abiotic conditions throughout the experiment.

\section{Statistical analysis}

To determine if each mesocosm could be regarded as independent, a preliminary Repeated Measures (RM) ANOVA was used to examine the effect of both experiment condition (control/drying) and duration (1, $7,14,21$ days) on the percentage survival (survivorship) of G. pulex. Mesocosm (1-5) was defined as a within-subject effect and experiment condition, duration and their interaction, were both defined as between-subject effects. Mauchly's tests were used to verify the RM ANOVA assumption of sphericity and the results of Greenhouse-Geisser tests were consulted when this assumption was violated. Mesocosm (RM ANOVA, Greenhouse-Geisser, $\left.F_{2.6}, 41.53=2, P=0.136\right)$ and its interaction with condition $\left(F_{2.6}, 41.53=2.348, P=0.095\right)$, duration
$\left(F_{7.8}, 41.53=2.348, P=0.065\right)$ and their interaction $\left(F_{7.8,41.53}=2.348, P=0.086\right)$ did not affect $G$. pulex survivorship and mesocosms could therefore be considered independent. General Linear Models (GLM) were used to examine the effect of experiment condition, duration and the change in abiotic parameters (end-start) on G. pulex survivorship. Experiment condition and duration were defined as fixed factors with survivorship defined as the dependent variable. Dissolved oxygen, $\mathrm{pH}$, water temperature and conductivity were defined as covariates. The effect of experiment condition and duration on these abiotic covariates was examined using GLM models by defining the mean abiotic parameters as dependent variables and experiment condition and duration as fixed factors. All analyses were conducted in IBM SPSS Statistics (version 23, IBM Corporation, New York).

\section{Results}

Overall, abiotic parameters during the experiments were similar (Table 1). Water $\mathrm{pH}$ and dissolved oxygen did not vary significantly between control and drying experiments (Table 2). Water temperature was marginally higher and conductivity was lower in drying experiments (Tables 1,2). Water temperature, conductivity and $\mathrm{pH}$ varied among experiment durations (Table 2).

Gammarus pulex survivorship decreased with increasing duration for both experiment conditions, but was reduced to a greater extent during the drying experiments (interaction term; GLM, $F_{3,112}=5.562$, $P=0.001$; Fig. 2). Within control experiments, $G$. pulex survivorship was similar after 1 and 7 days (Fishers LSD, $P=1)$. Mean survivorship $( \pm 2.08 \%$ SE) following control experiments was $100 \%$ after both 1 and 7 days and was reduced to $93 \%$ and $85 \%$ after 14 and 21 days. Mean survivorship following drying experiments was $100 \%$ after 1 day, but reduced to 89,79 and $70 \%$ after 7,14 and 21 days, respectively. When individual abiotic parameters were considered, change in $\mathrm{pH}$ (GLM, $F_{1,108}=0.701$, $P=0.404)$, dissolved oxygen $\left(F_{1}, \quad 108=0.114\right.$, $P=0.736)$, water temperature $\left(F_{1}, 108=0.167\right.$, $P=0.684) \quad$ or conductivity $\left(F_{1}, \quad 108=1.929\right.$, $P=0.168$ ) did not influence $G$. pulex survivorship. 
Table 1 Mean $( \pm 1 \mathrm{SE})$ values of $\mathrm{pH}$, dissolved oxygen, water temperature and conductivity after experiments in the control and drying condition

\begin{tabular}{|c|c|c|c|c|}
\hline \multirow[t]{2}{*}{ Parameter } & \multicolumn{4}{|c|}{ Duration (days) } \\
\hline & 1 & 7 & 14 & 21 \\
\hline \multicolumn{5}{|l|}{ Control condition } \\
\hline $\mathrm{pH}$ & $8.4 \pm 0.0$ & $8.4 \pm 0.0$ & $8.2 \pm 0.0$ & $8.2 \pm 0.0$ \\
\hline Dissolved oxygen $\left(\mathrm{mg} \mathrm{l}^{-1}\right)$ & $7.4 \pm 0.0$ & $7.3 \pm 0.0$ & $7.2 \pm 0.0$ & $7.3 \pm 0.0$ \\
\hline Water temperature $\left({ }^{\circ} \mathrm{C}\right)$ & $12.1 \pm 0.0$ & $12.1 \pm 0.0$ & $12.4 \pm 0.0$ & $12.3 \pm 0.0$ \\
\hline Conductivity $\left(\mu \mathrm{S} \mathrm{cm}^{-1}\right)$ & $513 \pm 1.2$ & $509 \pm 2.1$ & $572 \pm 6.9$ & $572 \pm 2.4$ \\
\hline \multicolumn{5}{|l|}{ Drying condition } \\
\hline $\mathrm{Ph}$ & $8.3 \pm 0.0$ & $8.3 \pm 0.0$ & $8.1 \pm 0.0$ & $8.3 \pm 0.0$ \\
\hline Dissolved oxygen $\left(\mathrm{mg} \mathrm{l}^{-1}\right)$ & $7.1 \pm 0.1$ & $7.2 \pm 0.1$ & $7.2 \pm 0.1$ & $6.9 \pm 0.1$ \\
\hline Water temperature $\left({ }^{\circ} \mathrm{C}\right)$ & $12.2 \pm 0.0$ & $13.1 \pm 0.1$ & $13.0 \pm 0.1$ & $12.7 \pm 0.1$ \\
\hline Conductivity $\left(\mu \mathrm{S} \mathrm{cm}^{-1}\right)$ & $512 \pm 3.5$ & $520 \pm 6.4$ & $485 \pm 4.5$ & $507 \pm 1.9$ \\
\hline
\end{tabular}

Table 2 General linear model (GLM) analysis of variation in abiotic parameter between control and drying experiments (experiment condition) and duration (1, 7, 14 and 21 days)

\begin{tabular}{|c|c|c|c|c|c|c|}
\hline \multirow[t]{2}{*}{ Abiotic parameter } & \multicolumn{3}{|c|}{ Experiment condition } & \multicolumn{3}{|c|}{ Duration } \\
\hline & $d f$ & $F$ & $P$ & $d f$ & $F$ & $P$ \\
\hline $\mathrm{pH}$ & 1 & 2.714 & 0.102 & 3 & 6.896 & $<0.001$ \\
\hline Dissolved oxygen & 1 & 1.517 & 0.221 & 3 & 1.580 & 0.198 \\
\hline Temperature & 1 & 44.458 & $<0.001$ & 3 & 9.894 & $<0.001$ \\
\hline Conductivity & 1 & 38.873 & $<0.001$ & 3 & 10.598 & $<0.001$ \\
\hline
\end{tabular}

Significant terms are emboldened

\section{Discussion}

Survivorship was lower for drying experiments compared to experiments in which surface water persisted. Our findings support those of previous laboratory studies, which have reported a reduction in gammarid survival in response to drying (Poznańska et al., 2013; Vander Vorste et al., 2016b). The limitation of these studies has often been the short experimental durations, from hours (Vadher et al., 2015) to approximately a week (e.g. Poznanska et al., 2013; Vander Vorste et al., 2016b), leaving the effect of longer drying durations on gammarid survival uncharacterized. Vadher et al. (2015) observed limited vertical movements and stranding above the water line in $2 \mathrm{~h}$ dewatering experiments as fine sediment reduced sediment porosity in mesocosms of identical design to those used in this experiment. By extending the experimental duration, the current study extends our understanding of $G$. pulex response to surface water loss. The increased experimental duration may have enabled any stranded individuals to move vertically within the moist subsurface sediments back into the saturated sediments. Gammarus pulex survivorship remained relatively high following 7 days of surface water loss compared to Vander Vorste et al. (2016b), who reported survival of up to $71 \%$ after 7 days in mesocosms experiencing water level reduction to $30 \mathrm{~cm}$ below the substrate surface. Survivorship in our experiments may have been higher due to the relatively short vertical distance required to move for $G$. pulex individuals to remain submerged.

Medium to coarse gravel particle sizes used in our study were unlikely to have impeded vertical movement of G. pulex into the subsurface (Vadher et al., 2017) and the excess leaf litter provided a plentiful food source. Subsurface leaf litter in coarse gravels has been reported as an important food source for detritivores such as gammarids (Navel et al., 2010). At the end of the experiments we observed an excess of leaf litter in the sediments which combined with the high survivorship in both the control and drying conditions, 


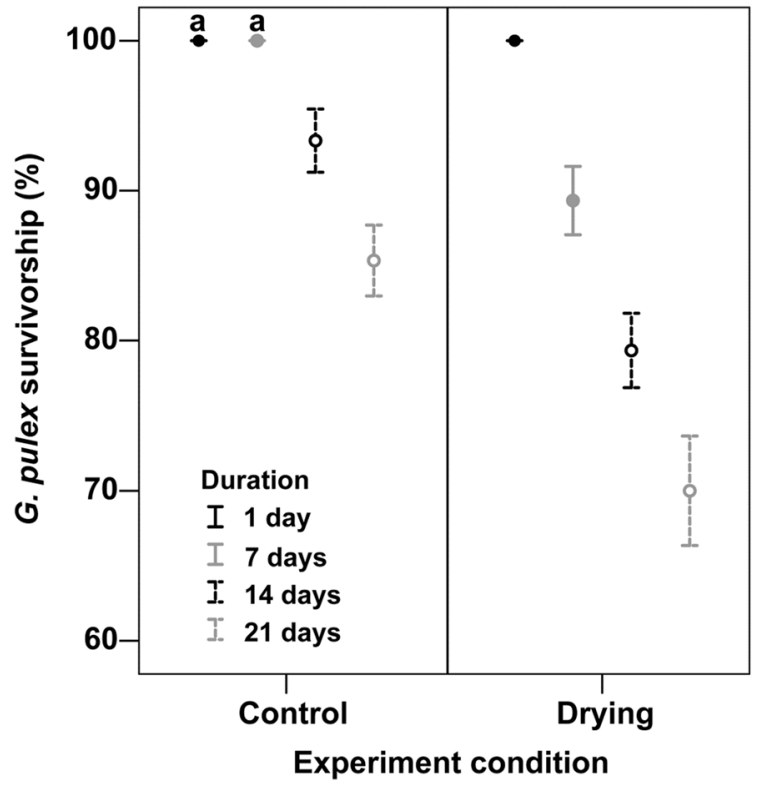

Fig. 2 Mean ( $\pm 1 \mathrm{SE})$ Gammarus pulex survivorship after each experiment duration. The left pane shows the control condition, and the right pane shows the drying condition. Letter ' $a$ ' indicates values which are not statistically different in the control experiment (Fisher's LSD, $P>0.05$ ). $Y$ axis starts at $60 \%$

which suggests that intraspecific predation was limited if it occurred (McGrath et al., 2007; Stubbington, 2012). Given that abiotic conditions and food resource availability were comparable (with the exception of water level) our results clearly illustrate the effect of channel drying on the survivorship of G. pulex.

Our experiments provide clear evidence that increasing drying duration reduces survivorship. This finding supports our observations made as part of a mesocosm-based field experiment investigating the effect of identical drying durations (7, 14 and 21 days) on the survivorship of G. pulex (Vadher et al., 2018). Under field conditions, G. pulex survivorship was approximately 65,60 and $51 \%$ following 7, 14 and 21 days of dry periods, respectively (Vadher et al., 2018). In the current investigation, the effect of drying duration on survivorship was reduced compared to this field study (the lowest mean survivorship recorded was $70 \%$ after 21 days of drying in the current experiment), almost certainly reflecting the relative stability of other abiotic variables within the laboratory flume compared to field conditions. This study provides supporting evidence that the hyporheic zone functions as a refuge for benthic invertebrates if environmental parameters (e.g. water quality and food resources) remain favourable (Hose et al., 2005; Fenoglio et al., 2006; Vander Vorste et al., 2016a). However, the relationship between survivorship and drying duration appears to be linear (Fig. 2). This indicates that subsurface sediments may be limited in their long-term refuge potential for taxa typically associated with perennial waterbodies, such as $G$. pulex, although some taxa which display adaptations to such conditions, such as some adult Coleoptera, have been recorded to persist in an active state for much longer durations in the field (e.g. Fenoglio et al., 2006). Further study is required to explore the effect of the duration of drying on macroinvertebrate taxa associated with temporary waters so that speciesspecific responses to drying can be quantified. This should include species from streams that dry irregularly or partially (e.g. into isolated pools-Hill \& Milner 2018) and should also consider patterns of drying and proximity of perennial waterbodies and refuges (Wood et al., 2005; White et al., 2018).

The results of this study support field investigations highlighting the effect of streambed drying on instream faunal densities (e.g. Clarke et al., 2010; Datry et al., 2014; Bogan et al., 2015; Verdonschot et al., 2015). Specifically, our results show that surface drying reduces survivorship within subsurface sediments, and that this reduction increases over time. However, field studies often highlight the effect of other, usually interacting, abiotic parameters associated with channel drying (e.g. low dissolved oxygen, high conductivity and elevated water temperatures; Bond et al., 2008; Verdonschot et al., 2015). This laboratory-based mesocosm study demonstrates that ex situ experiments can facilitate understanding of the influence of abiotic factors by specifically manipulating them or holding them constant (Vadher et al., 2015, 2017; Vander Vorste et al., 2016b, 2017).

The results of this experimental study have wider implications for the study of temporary streams since they demonstrate that some common benthic fauna, such as G. pulex, can persist in subsurface sediments and the hyporheic zone following channel drying for at least 21 days and potentially longer. The experimental study provides further empirical evidence to support for the Hyporheic Refuge Hypothesis (Williams \& Hynes, 1974) under low flow and channel drying conditions (Hose et al., 2005; Fenoglio et al., 2006; Wood et al., 2010) where the presence of free water 
and abiotic conditions remain suitable for taxa to persist. However, the results highlight that knowledge of the habitats used, faunal traits that confer persistence, and the mechanisms employed by generalist and temporary water specialist taxa during channel drying events remain poorly quantified (Stubbington et al., 2016). Many temporary stream specialist taxa do not typically co-exist at sites with large numbers of ubiquitous taxa, such as G. pulex (White et al., 2018). The present study results suggest that this lack of coexistence probably reflects the local exclusion of ubiquitous taxa, such as G. pulex, when drying duration increases, although the ability of taxa to persist longer periods of drying requires further research.

The predicted effects of climate change and increasing demands on water resources are likely to increase the frequency and duration of stream drying events (Ledger \& Milner, 2015; Pyne \& Poff, 2017). The effect of increasing drying duration on G. pulex survivorship could have consequences that reverberate throughout food webs if processing of coarse organic matter is reduced (Ledger et al., 2011). Given the linear relationship between $G$. pulex survivorship and drying duration, longer experiments are required to advance understanding of the effects of drying duration on survivorship and potential consequences for ecosystem functioning. This study provides further evidence of the need for effective refuge restoration and management in streams and the maintenance of streambed sediments to enhance vertical connectivity (Boulton et al., 2010). Quantifying the effects of drying and refuge use is therefore important, and future research should consider combined field and mesocosm-based approaches to facilitate greater understanding.

Acknowledgements We thank Nottingham Trent University, School of Science and Technology for providing access to the flume facility and are grateful to Mick Shaw, Jacqueline Greef and Jayne Spence for technical support. Atish N. Vadher gratefully acknowledges the provision of a studentship from the School of Social, Political and Geographical Sciences at Loughborough University for funding this research. We thank the field and laboratory assistance of Louis Durrant. We would like to thank the Associate Editor and two anonymous reviewers for their comments.

Open Access This article is distributed under the terms of the Creative Commons Attribution 4.0 International License (http:// creativecommons.org/licenses/by/4.0/), which permits unrestricted use, distribution, and reproduction in any medium, provided you give appropriate credit to the original author(s) and the source, provide a link to the Creative Commons license, and indicate if changes were made.

\section{References}

Arscott, D. B., S. Larned, M. R. Scarsbrook \& P. Lambert, 2010. Aquatic invertebrate community structure along an intermittence gradient: Selwyn River, New Zealand. Journal of the North American Benthological Society 29: 530-545.

Bogan, M. T., K. S. Boersma \& D. A. Lytle, 2015. Resistance and resilience of invertebrate communities to seasonal and supraseasonal drought in arid-land headwater streams. Freshwater Biology 60: 2547-2558.

Bond, N. R., P. S. Lake \& A. H. Arthington, 2008. The impacts of drought on freshwater ecosystems: an Australian perspective. Hydrobiologia 600: 3-16.

Boulton, A. J., 2003. Parallels and contrasts in the effects of drought on stream macroinvertebrate assemblages. Freshwater Biology 48: 1173-1185.

Boulton, A. J., T. Datry, T. Kasahara, M. Mutz \& J. A. Stanford, 2010. Ecology and management of the hyporheic zone: stream-groundwater interactions of running waters and their floodplains. Journal of the North American Benthological Society 29: 26-40.

Chessman, B. C., 2009. Climatic changes and 13-year trends in stream macroinvertebrate assemblages in New South Wales, Australia. Global Change Biology 15: 2791-2802.

Chester E. T. \& B. J. Robson, 2011. Drought refuges, spatial scale and recolonisation by invertebrates in non-perennial streams. Freshwater Biology 56: 2094-2104.

Clarke, A., R. MacNally, N. Bond \& P. S. Lake, 2010. Flow permanence affects aquatic macroinvertebrate diversity and community structure in three headwater streams in a forested catchment. Canadian Journal of Fisheries and Aquatic Sciences 67: 1649-1657.

Datry, T., 2012. Benthic and hyporheic invertebrate assemblages along a flow intermittence gradient: effects of duration of dry events. Freshwater Biology 57: 563-574.

Datry, T., S. T. Larned \& M. R. Scarsbrook, 2007. Responses of hyporheic invertebrate assemblages to large-scale variation in flow permanence and surface-subsurface exchange. Freshwater Biology 52: 1452-1462.

Datry, T., S. T. Larned, K. M. Fritz, M. T. Bogan, P. J. Wood, E. I. Meyer \& A. N. Santos, 2014. Broad-scale patterns of invertebrate richness and community composition in temporary rivers: effects of flow intermittence. Ecography 37 : 94-104.

del Rosario, R. B. \& V. H. Resh, 2000. Invertebrates in intermittent and perennial streams: is the hyporheic zone a refuge from drying? Journal of the North American Benthological Society 19: 680-696.

Descloux, S., T. Datry \& P. Marmonier, 2013. Benthic and hyporheic invertebrate assemblages along a gradient of increasing streambed colmation by fine sediment. Aquatic Sciences 75: 493-507.

Dewson, Z. S., A. B. W. James \& R. G. Death, 2007. A review of the consequences of decreased flow for instream habitat 
and macroinvertebrates. Journal of the North American Benthological Society 26: 401-415.

Feminella, J. W., 1996. Comparison of benthic macroinvertebrate assemblages in small streams along a gradient of flow permanence. Journal of the North American Benthological Society 15: 651-669.

Fenoglio, S., T. Bo \& G. Bosi, 2006. Deep interstitial habitat as a refuge for Agabus paludosus (Fabricus) (Coleoptera: Dytiscidae) during summer droughts. Coleopterists Bulletin 60: $37-41$.

Hill, M. J. \& V. S. Milner, 2018. Ponding in intermittent streams: a refuge for lotic taxa and a habitat for newly colonising taxa? Science of the Total Environment 628-629: 1308-1316.

Hose, G. C., P. Jones \& R. P. Lim, 2005. Hyporheic macroinvertebrates in riffle and pool areas of temporary streams in south eastern Australia. Hydrobiologia 532: 81-90.

Lake, P. S., 2003. Ecological effects of perturbation by drought in flowing waters. Freshwater Biology 48: 1161-1172.

Lake, P. S., 2011. Drought and Aquatic Ecosystems: Effects and Responses. Wiley-Blackwell, Oxford.

Lancaster, J. \& M. E. Ledger, 2015. Population-level responses of stream macroinvertebrates to drying can be density-independent or density-dependent. Freshwater Biology 60: 2559-2570.

Larned, S. T., T. Datry, D. B. Arscott \& K. Tockner, 2010. Emerging concepts in temporary-river ecology. Freshwater Biology 55: 717-738.

Lawrence, J. E., M. E. Skold, F. A. Hussain, D. R. Silverman, V. H. Resh, D. L. Sedlak, R. G. Luthy \& J. E. McCray, 2013. Hyporheic zone in urban streams: a review and opportunities for enhancing water quality and improving aquatic habitat by active management. Environmental Engineering Science 30: 480-501.

Ledger, M. E. \& A. M. Milner, 2015. Extreme events in running water. Freshwater Biology 60: 2455-2460.

Ledger, M. E., F. K. Edwards, L. E. Brown, A. M. Milner \& G. Woodward, 2011. Impact of simulated drought on ecosystem biomass production: an experimental test in stream mesocosms. Global Change Biology 17: 2288-2297.

MacNeil, C., J. T. A. Dick \& R. W. Elwood, 1997. The trophic ecology of freshwater Gammarus spp. (Crustacea: Amphipoda): problems and perspectives concerning the functional feeding group concept. Biological Reviews 72: 349-364.

Mathers, K. L., J. Millett, A. L. Robertson, R. Stubbington \& P. J. Wood, 2014. Faunal response to benthic and hyporheic sedimentation varies with direction of vertical hydrological exchange. Freshwater Biology 59: 2278-2289.

McGrath, K. E., E. T. H. M. Peeters, J. A. J. Beijer \& M. Scheffer, 2007. Habitat-mediated cannibalism and microhabitat restriction in the stream invertebrate Gammarus pulex. Hydrobiologia 589: 155-164.

Navel, S., F. Mermillod-Blondin, B. Montuelle, E. Chauvet, L. Simon, C. Piscart \& P. Marmonier, 2010. Interactions between fauna and sediment control the breakdown of plant matter in river sediments. Freshwater Biology 55: 753-766.

Poznańska, M., T. Kakarek, M. Krzyżyński \& J. Kobak, 2013. Effect of substratum drying on the survival and migrations of Ponto-Caspian and native gammarids (Crustacea: Amphipoda). Hydrobiologia 700: 47-59.

Pyne, M. I. \& M. I. Poff, 2017. Vulnerability of stream community composition and function of projected thermal warming and hydrologic change across ecoregions in the western United States. Global Change Biology 23: 77-93.

Robson, B. J., E. T. Chester \& C. M. Austin, 2011. Why life history information matters: drought refuges and macroinvertebrate persistence in non-perennial streams subject to a drier climate. Marine and Freshwater Research 62: 801-810.

Storey, R., 2016. Macroinvertebrate community responses to duration, intensity and timing of annual dry events in intermittent forested and pasture streams. Aquatic Sciences 78: 395-414.

Strachan, S. R., E. T. Chester \& B. J. Robson, 2015. Freshwater invertebrate life history strategies for surviving desiccation. Springer Science Reviews 3: 57-75.

Stubbington, R., 2012. The hyporheic zone as an invertebrate refuge: a review of variability in space, time and behaviour. Marine and Freshwater Research 63: 293-311.

Stubbington, R., A. M. Greenwood, P. J. Wood, P. D. Armitage, J. Gunn \& A. L. Robertson, 2009. The response of perennial and temporary headwater stream invertebrate communities to hydrological extremes. Hydrobiologia 630: 299-312.

Stubbington, R., J. Gunn, S. Little, T. P. Worrall \& P. J. Wood, 2016. Macroinvertebrate seedbank composition in relation to antecedent duration of drying and multiple wet-dry cycles in a temporary stream. Freshwater Biology 61: 1293-1307.

Stubbington, R., J. P. Hogan \& P. J. Wood, 2017. Characterization of the density and body size of a Gammarus pulex (Crustacea: Amphipoda) population in subsurface sediments reflects the sampling technique used. Hydrobiologia 788: 293-303.

Vadher, A. N., R. Stubbington \& P. J. Wood, 2015. Fine sediment reduces vertical migrations of Gammarus pulex (Crustacea: Amphipoda) in response to surface water loss. Hydrobiologia 753: 61-71.

Vadher, A. N., C. Leigh, J. Millett, R. Stubbington \& P. J. Wood, 2017. Vertical movements through subsurface stream sediments by benthic macroinvertebrates during experimental drying are influenced by sediment characteristics and species traits. Freshwater Biology 62: 1730-1740.

Vadher, A. N., J. Millett, R. Stubbington \& P. J. Wood, 2018. Drying duration and stream characteristics influence macroinvertebrate survivorship within the sediments of a temporary channel and exposed gravel bars of a connected perennial stream. Hydrobiologia 814: 121-132.

Vander Vorste, R., F. Malard \& T. Datry, 2016a. Is drift the primary process promoting the resilience of river invertebrate communities? A manipulative field experiment in an intermittent alluvial river. Freshwater Biology 61: 1276-1292.

Vander Vorste, R., F. Mermillod-Blondin, F. Hervant, R. Mons, M. Forcellini \& T. Datry, 2016b. Increased depth to the water table during river drying decreases the resilience of Gammarus pulex and alters ecosystem function. Ecohydrology 9: 1177-1186. 
Vander Vorste, R., F. Mermillod-Blondin, F. Hervant, R. Mons, M. Forcellin \& T. Datry, 2017. Gammars pulex (Crustacea: Amphipoda) avoids increasing water temperature and intraspecific competition through vertical migration into the hyporheic zone: a mesocosm experiment. Aquatic Sciences 79: 45-55.

Verdonschot, R. C. M., A. M. van Oosten-Siedlecka, C. J. F. ter Braak \& P. F. M. Verdonschot, 2015. Macroinvertebrate survival during cessation of flow and streambed drying in a lowland stream. Freshwater Biology 60: 282-296.

White, J. C., A. House, N. Punchard, D. M. Hannah, N. A. Wilding \& P. J. Wood, 2018. Macroinvertebrate community responses to hydrological controls and groundwater abstraction effects across intermittent and perennial headwater streams. Science of the Total Environment 610-611: 1514-1526.
Williams, D. D. \& H. B. N. Hynes, 1974. The occurrence of benthos deep in the substratum of a stream. Freshwater Biology 4: 233-256.

Wood, P. J., J. Gunn, H. Smith \& A. Abas-Kutty, 2005. Flow permanence and macroinvertebrate community diversity within groundwater dominated headwater streams and springs. Hydrobiologia 545: 55-64.

Wood, P. J., A. J. Boulton, S. Little \& R. Stubbington, 2010. Is the hyporheic zone a refugium for aquatic macroinvertebrates during severe low flow conditions. Fundamental and Applied Limnology 176: 377-390.

Young, B. A., R. H. Norris \& F. Sheldon, 2011. Is the hyporheic zone a refuge for macroinvertebrates in drying perennial streams? Marine and Freshwater Research 62: 1373-1382. 